\title{
Editors’ Introduction
}

\section{GLYN HAMBROOK AND GABRIELA STEINKE}

This double issue of Comparative Critical Studies offers, in keeping with tradition, a selection of essays based on papers delivered at a Triennial International Conference of the British Comparative Literature Association (BCLA), in this case the fourteenth in the series, the topic of which was 'Salvage'.

Hosted by the University of Wolverhampton, the 'Salvage' conference took place between 12 and 15 July 2016. It attracted over ninety delegates from twenty countries from across the globe, not counting the three UK nations represented (England, Wales, Scotland). This geocultural diversity is reflected in the twelve essays deriving from papers delivered at the conference that have been selected for inclusion in this double issue of Comparative Critical Studies.

The conference opened with a plenary panel convened by Professor Marina Warner, whose opening address, delivered in absentia, was followed by papers by Professor Duncan Large, Dr Dorota Goluch and Dr Richard Hibbett. In the course of the conference, which spanned four days, four plenary lectures were delivered by, successively, Professor Dámaso López García of the Universidad Complutense de Madrid, Spain, who reminded delegates of the contemporary resonances of Cervantes and Shakespeare, both of whom had died 400 years previously; Professor Holger Klein of the University of Vienna, a founder member of the BCLA when at UEA in 1975, who reviewed critical assessments of Shakespeare's Falstaff; Professor Susan Jones, University of Oxford, whose lecture on literature and dance offered a timely reminder that one of Comparative Literature's fields of enquiry is the relationship between literature and other artistic discourses; and Emeritus Professor (Queens College, Oxford) David Constantine, who concluded the conference with an insightful and 
moving reflection on the conference theme of salvage that interwove personal memory and world literature in the centenary year of the battle of the Somme and at a time when strife and schism beset the world. The plenary papers will be gathered in the 2017 issue of $e$-CCS, the electronic supplement of this journal.

In the wake of the conference over twenty emails were received from delegates praising the choice of theme, the quality of the papers and the hospitality of the host institution and team, which included an international welcome-and-help team of six undergraduate and postgraduate students. The conference was organised by members of the Centre for Transnational and Transcultural Research and other colleagues from the Faculty of Arts, and academic quality was overseen by a Scientific Committee made up of UK and international scholars. The guest editors wish to express their thanks to the members of this Committee for their support, assistance and cooperation during the edition of this special issue.

It is worth noting at this juncture that the conference was something of an exercise in outreach. The host institution is not known as a centre for comparative literature and, although home to a clutch of committed comparatists, it neither boasts a unit nor offers a course in comparative literature. This is not typical of the region: Warwick University, at the other end of the West Midlands conurbation, is a distinguished centre of comparative literary studies of long standing. Other Midlands universities, such as Nottingham and Aston, contributed to the discipline's recent expansion. The University of Wolverhampton is, however, representative of those newer UK universities that are beginning to acknowledge the comparative turn in literary studies; a move away from the national paradigm and from the classification of literature in terms of monolingual units, prompted by a growing awareness of the inevitably and unavoidably transnational character of cultural production, of the monde sans frontières of a world literature that has succeeded in transcending its original guise as just another project of the cultural Anglosphere. To this end, 
Wolverhampton, in an alliance with Birmingham City and Keele Universities - all of which lacked (because they had either lost it or never had it) a typical ingredient of a 'comparative literature institution's’ portfolio: a modern languages department - founded in 2015 the Northern Comparative Literature Network, with the aim of promoting the comparative study of literature in institutions without the typical infrastructural profile and of providing a platform and forum for comparatists from such institutions.

\section{THE CONFERENCE THEME}

'Salvage', although this may not be apparent at first sight, is a concept at the very heart of much literary and cultural activity. Translation, reception, re-reading - the vital substance of comparative literary research - all refer to processes by which literature's significance is activated or released in acts of salvage, acts of saving and, indeed, salvation. The richness of the topic and the wealth of nuances and inflections that it embodies became apparent as the Organising and Scientific Committees jointly 'brainstormed' to find a comprehensive selection of keywords that reflected the diverse semantic orientations and axes of the concept of 'Salvage'. The following seven semantic domains, which do not claim to be exhaustive, were those eventually chosen to awaken inspiration in potential contributors:

1. Retrieval: recuperation, recovery, rediscovery, exhumation, remembering, recollecting, resurrection, repossession;

2. Saving: rescue, survival, reprieve, restoration, resuscitation, repair, preservation, conservation, consecration, canonization, quotation, re-edition, translation, legitimisation, de-criminalization;

3. Saving the spirit: redemption, salvation, renaissance, rebirth, liberation, emancipation; 
4. Re-using: recycling, re-processing, triage, bricolage, ecology, scavenging, transformation, imitation, plagiarising, transmutation, adaptation, metamorphosis, anniversary, commemoration;

5. Reconfiguring: blending, merging, distilling, filtering, abstracting, editing, expurgating, bowdlerising, disguising, distortion;

6. Remains: rubbish, gold under dirt, detritus, ruins, monuments, residue, ecology, collage;

7. The antithesis of salvage: suppression, censorship, stigmatization, defamation, repression, eradication, erosion, disarticulation, oblivion, forgetting.

A number of these terms found their way into the paper proposals submitted and have indeed survived the processes of filtration and transformation that characterise the transition from conference paper to essay.

\section{THE ESSAYS}

The essays selected for inclusion in this issue of Comparative Critical Studies approach the topic of salvage in a variety of ways, which in spite of their diversity lend themselves to systematic classification, according to how, or more precisely in what specific guises, literary scholarship enacts or invokes salvage either as a matter of course or as a specific ambition. The frequency of choice of certain keywords in this type of essay can serve as an indicator of possible ways. We may then consider how critical readers, be these critics themselves or reader-writers as subjects of critical interest, interpret or 'appropriate' salvage or its subvarieties to refer to specific contexts or situations, investing the concept with specific meaning or specific inflexions in order better to grapple with the context. The relationship 
between salvage and the act of reading, or reading as salvage thus become relevant topics of investigation.

\subsection{CRITICAL RECUPERATIONS}

Some of the essays gathered in this issue (those of Brown, Guimarães, Orzóy) enact the conference’s key concept themselves, 'salvaging' works, authors or readings that had been forgotten, neglected or marginalised. This prompts in turn a reflection on what causes texts, their producers or certain interpretations of them to be overlooked, side-lined or suppressed and, conversely, what credentials a work, author or reading is are required to display or embody in order to merit consecration in some guise or another. Penny Brown's exploration of Manga versions of Shakespeare and Cervantes - an eminently topical choice of authors for this conference, as the conference year of 2016 marked the $400^{\text {th }}$ anniversary of the deaths of both Miguel de Cervantes and William Shakespeare - is predicated on keywords both drawn from the conference list - salvage - while adding to that repertoire retellings and rewritings (equally at home under our headings of re-using or reconfiguring), revival, recreation and rejuvenation, notions in which our sub-concepts of retrieval and saving converge. This list is rounded off with 'cultural authority', a key consideration in the transfer of 'high' cultural text to a popular cultural medium such as Manga. This essay, which in its comprehensive approach to the concept of salvage, crosses the boundaries of our editorial classification of essays by approach to the conference topic, explores primarily how the intermedial transposition of works conventionally linked to 'high' culture to a more popular cultural form effectively constitutes an act of salvage that revivifies these works, not least by making them accessible to new audiences. This views counters any residual suspicion that the passage from high to popular culture constitutes some form of debasement, to use Brown's term. 
Paula Guimarães's study of the critically neglected production of three women poets (Augusta Webster, Mathilde Blind and Amy Levy) in fin-de-siècle Britain takes the conference's sub-concept of transformation, in this case of myth and of the past, as a central trope of the poets' work but one that has ironically passed unacknowledged as characteristically fin-de-siècle, while also paying close attention to the notion of cultural recuperation and rediscovery which, she argues, not only enriches the history of poetry, particularly women's poetry, but also leads to an appreciation of the contemporary relevance of the works discussed.

Ágnes Orzóy’s study of three Hungarian texts - Imre Kertész’s Fatelessness, Teréz Rudnóy’s Women Getting Free, and the wartime diary of Fanni Gyarmati - discovers salvage in the form of rediscovery through multidirectional memory of displaced meanings in the face of what we have termed salvage's antithesis: suppression, oblivion - the risks run by memories that cultural memory, ritualized by historiography and politics, can find difficult to assimilate. The essay also posits reading from the perspective of cultural memory as a viable approach to literary and other texts.

\subsection{THE POETICS OF SALVAGE}

Other essays in this issue focus on 'salvage' as a literary strategy, technique, mode of operation or ambition, considering how literature enacts salvage within its own textual but permeable boundaries. It is via this mode of enquiry that our authors had recourse to the more nuanced forms of salvage enumerated in - and beyond - the keywords, homing in on one particular form or invoking several according to the case or occasion in question. It is within this category that we can place the essays on what might be referred to as identitarian ambivalence, ambiguity and limbo, be these intercultural (Espino Barrera, Filipovic) or corporeal (Weber); or intertextuality, which can be further subdivided into focuses on the one 
hand on rewriting and adaptation (Brown, again, Bührle and Pujol-Valls) and on the other hand as intertextuality or in relation to salvage or salvation (Agarwal, Im, Mohammadi, Tales).

\subsubsection{IDENTITARIAN SALVAGE}

As regards the first sub-category, Tomás Espino Barrera focuses on issues of linguistic identity in the specific form of bilingual or plurilingual authors' relationships with the two or more languages that they use, in an essay that considers translingualism within the eminently topical contexts of exile and migration and which, not surprisingly therefore, is predicated on the concepts of survival, preservation, adaptation, liberation, censorship and attrition. Espino Barrera argues that infusing the mother tongue with attributes of kinship and affect enact in effect a form of salvation from the trauma of linguistic exile that frequently expresses itself through metaphors of illness and death.

Zlatan Filipovic, in a similar contextual orientation, offers an analytical reflection on the psycho-philosophical dilemma underpinning diasporic experience in an essay that invokes a wide range of theme-related concepts, which he divides into more or less frequent inflections. The former comprise salvage, holding on, vestige, reconstitution, the unsalvageable, and disavowal; the latter, maintaining, preservation, residue, loss, letting go, effacement, and disarticulation. For Filipovic, the exigencies that the present places on the diasporic subject render the past effectively unsalvageable. In this context, shame emerges as an aspect of the diasporic identity as 'a residue of the unsalvageable past', while mimicry is revealed to be a coping strategy based on disavowal of the past that nonetheless fails. Filipovic's essay may be profitably read not only in conjunction with Espino Barrera’s but also Orzóy’s, by virtue of their common engagement with various types of tension and conflict between past and present. 
Drawing on the concepts of salvage, salvation, repression and eradication, Stephanie Weber's essay explores how the reconfiguration and re-positioning of corporeal norms are enacted in literary representations of the freak. Central to Weber's essay, which takes as its focal text Katherine Dunn's novel Geek Love, is the idea of the promise of salvation through the transcendence of corporeal and attitudinal norms - a salvation to be achieved not by denying or suppressing the grotesque but by in effect sanctifying it, by rendering it holy. From this emerges an aesthetics of the grotesque, as it were, in which emphasis or enhancement of the grotesque becomes a means to foreground that element of its ambivalent nature that comprises modernity's equation of beauty with the bizarre.

\subsubsection{INTERTEXTUALITY: REWRITING AND ADAPTATION}

Moving on to the second sub-category, both Penny Brown and Maria Pujol-Valls consider textual migration between young and older (or more general) communities of readers engineered or facilitated by re-writings of works written for or, less intentionally, associated with a particular readership. Both Brown and Julia Bührle look beyond genre across art forms, considering the transposition of literary or dramatic antecedents into the graphic novel and ballet respectively. Bührle contemplates a period in the history of European ballet that saw a recycling and adaptation of both older literary texts and older ballet libretti as well as featuring heroines that save their lovers from physical and/or spiritual destruction while at the same time either sacrificing (frequently) or attaining (occasionally) their own salvation. She argues that changes in the physical conditions of ballet (pointe shoes and lighter dresses) facilitated a more active role for ballerinas than had been traditional, so that women could become the instigators of salvation, but that male sensibilities were salved by the traditional notion of the self-sacrificing woman, as in the notorious Giselle and its many variations. 
Maria Pujol-Valls's reflection on rewritings of Robinson Crusoe and Treasure Island by Catalan author Josep Vallverdú, known primarily as a writer of children's literature, is predicated on the concepts of recovery, translation, transformation, adaptation. In her essay, Pujol-Valls discusses the possible impact on his own culture of a well-loved writer's adaptation and appropriation of two texts in the English-language canon, Robinson Crusoe and Treasure Island, by writing sequels in Catalan. She looks at how Josep Vallverdú's experience as a writer and translator enabled him to transpose the action and characters of the original novels into a contemporary context, and how the peripheral status of the Catalan language and culture may influence how the author adapts a more hegemonic language and culture.

\subsubsection{INTERTEXTUALITY AND/AS SALVATION}

In the third and final sub-category, Megha Agarwal's essay, which lists as a keyword 'literary relations', explores intertextuality as a means of salvation through re-use (re-writing, imitation, metamorphosis, scrounging) and saving (salvation, redemption) and reconfiguration (distortion). Salvation or its elusiveness is explored through intertextuality as a vehicle for the salvage, appropriation and reimagining of Dante and Milton by Joseph Conrad and Mary Shelley respectively. Agarwal offers a reading of Dante and Milton as guides for the later authors who modify the epic journeys of their predecessors and in the process also enable the reader to review the ideas about life, death, the afterlife and salvation or damnation found in the earlier texts.

Yeeyon Im's contribution focuses on theo-philosophical rather than literary antecedents in the 'ghost-plays' of W. B. Yeats in its exploration of the impact of Indian religious thought on the Irish writer's work, with particular reference to salvation through reincarnation. Im casts her net wide when looking at influences on Yeats's ghost plays beyond the classical 
European ones. She contends that when Yeats in effect denies the possibility of salvation, and even its precursor, purgation, he is harking back to what he had learned of Indian, both Buddhist and Hindu philosophies and adapting them for his own purposes. Beside a fairly broad streak of degeneration theory, she finds evidence of Hindu teachings in the Old Man's inability to shake off his earthly shackles and proceed via a catholic idea of purgatory to the pan-Christian salvation; in the process, she shows Yeats as a comparatist forerunner.

In similar fashion, Marjan Mohammadi considers the presence and antecedence of John Calvin's thought in Thomas Pynchon's Gravity's Rainbow from the perspective of the concept of preterition. Salvation, waste and synthesis figure as key sub-manifestations of salvage in this essay. She investigates the possibility (or impossibility) of salvation in Pynchon's novel, and argues that he takes aim at what he sees as the pervasive Calvinist notion of preterition and the narrowly linear and capitalist narrative of human development and national identity it engendered in the United States of America. The resulting proliferation of waste, unrecycled and unreclaimed, amid the rise of technology in an increasingly secular society renders the promised land into a wasteland of lost souls.

Bryn Tales’s re-reading of Muriel Rukeyser's Book of the Dead, inspired by the Hawk's Nest Tunnel mining disaster in the US in the late 1930s, explores how poetry salvages from silence the miners' suffering by reclaiming the experience of the disaster via its material signs and symbols, in a manner similar to that propounded by Walter Benjamin in his midtwentieth century theories on poetry and history and enacted by Herman Melville in his use of the poetic symbol, both of whose work serves as intertextual points of reference in this essay. For Tales, this salvaging process involves the reclamation of symbolic meaning in and through art, lyrical responses to these symbolic articulations and the material 'objects' of experience such as statistics and cartographies. 


\subsection{THE COMPARATIVE PERSPECTIVE}

Finally, it behoves us to consider the role and place of comparative methodology in the context of salvage. From a purely pragmatic perspective, it is worth noting that there can be a temptation, when invited to compose to a theme, to subordinate a comparative approach to adherence to that theme, or even to allow oneself to overlook the comparative perspective, especially for a scholar not given to comparative practice. Yet as the mission of the BCLA is specifically comparative, the conference's scientific committee sought to adopt and maintain throughout a comparative criterion in the assessment of abstracts and subsequently selection of essays for inclusion, as well as in the stages of revision through which each selected contribution went on the way to acquiring the form in which the reader of this issue will encounter it. The comparative approach finds its place in this selection of essays in a variety

of guises: reception (Agarwal, Brown, Bührle, Im, Mohammadi, Pujol-Valls), intertextuality (Agarwal, Brown, Bührle, Im, Mohamadi, Pujol Valls), comparison across genre (Brown, Pujol Valls), form (Brown, Bührle) and discourse (Im, Mohammadi), the intercultural (Espino Barrera, Filipovic), inter-authorial and inter-textual comparison (Filipovic, Espino Barrera, Guimarães, Orzóy, Tales).

Not completely unrelated to this is a trend that has emerged recently in comparative literary studies, namely increased attention to Anglophone literatures on the part of nonAnglosphere scholars. This is in a sense in keeping with the traditional comparatist's view that the knowledge of at least one foreign language - in this case English - is a prerequisite for being considered a comparatist. Yet it is also giving notice that the monolithic monolingual institutions in literary studies, such as university units within one country that concern themselves with that very country's literature - 'their' literature, as it is often deemed to be, and sometimes irreflexively - need to take on board the not inconsiderable 
pool and stream of scholarship on that literature by 'non-natives'. The position of such scholarship in a particular linguistic and cultural environment may be considered to constitute in itself a form of comparative reading, since the 'non-native' can bring to bear a range of 'alien' criteria (assumptions, habitual practices, cultural lenses) different to those that the scholar of their 'own' literature can bring, in addition to being familiar with what the 'natives' perspectives on their 'own' literature are. This leads on to a theory of reading that comparatism has repeatedly shown itself to be willing to embrace: one based not on a 'fallacy of origin' - the idea that 'we' know and understand 'our' literature better than anyone else that ascribes meaning to literature in terms of provenance, but one that ascribes meaning to literature according to its reception - a timely acknowledgement of the undeniably transnational nature of literature: literature travels, and has always been sans frontières.

\section{EPILOGUE: A NEW PHASE}

This double issue of Comparative Critical Studies also marks a moment of transition. The coeditors since 2012, Maike Oergel and Glyn Hambrook, are handing over the reins to a new, larger editorial team. The expansion of the editorial team responds to the increase in interest in and implantation of comparative literature in the UK, which has gone hand in hand, particularly during the last 'long lustrum', with growing awareness among scholars in the field of the diverse national literatures of the merits of an approach that places these literatures in relation to each other as well as, and possibly leading to, the marked increase in submissions, not least from contributors from outside the UK, that has been registered since the second decade of the twenty-first century. The outgoing editors are conscious of the team effort that has underpinned engagement with this new trend, and they would like to express their unconditional gratitude to their colleagues Richard Hibbitt and Rosa Mucignat, who in 
their respective capacities as assistant editor and reviews editor provided inestimably valuable support, displaying not only selfless devotion to duty but unstinting professionalism in the acquittal of their responsibilities during this period of the journal's life. Both colleagues will remain on the editorial team: Richard Hibbitt will be joined by fellow BCLA Executive Committee members Will McMorran and Francesca Orsini to form the new editorial core, while Rosa Mucignat will continue in her role as reviews editor.

The last editorial term of office also witnessed fundamental changes in academic publishing, from the dramatic rise in e-publishing to the shift towards open access publication, driven in the UK by the Research Excellence Framework. It was in response to the former that Comparative Critical Studies' electronic 'supplement', e-CCS, the brainchild of Maike Oergel, was launched in 2013. At this time of opportunities and challenges, the outgoing editors extend their wishes to the incoming team for a fruitful next stage in the journal's trajectory.

Finally, the outgoing editors would like to express their gratitude to colleagues at Edinburgh University Press with whom they collaborated in the production of the journal, particularly Ann Vinnicombe, for whose support, advice and forbearance they are particularly grateful. 